\title{
BMJ Open Examination of patient characteristics and hydroxychloroquine use based on the US Food and Drug Administration's recommendation: a cross-sectional analysis in New York
}

\author{
Eun Ji Kim (D) , ${ }^{1,2}$ Kevin Coppa, ${ }^{3}$ Jamie S Hirsch, ${ }^{1,2,3}$ Sara Abrahams, ${ }^{1}$ \\ Jennifer Johnson, ${ }^{2}$ Martin Lesser, ${ }^{1,2,4}$ Karina W Davidson, ${ }^{1,2}$ Joseph Conigliaro, ${ }^{1,2}$ \\ and the Northwell Health COVID-19 Research Consortium
}

To cite: Kim EJ, Coppa K, Hirsch JS, et al. Examination of patient characteristics and hydroxychloroquine use based on the US Food and Drug Administration's recommendation: a cross-sectional analysis in New York. BMJ Open 2021;11:e042965. doi:10.1136/ bmjopen-2020-042965

- Prepublication history for this paper is available online To view these files, please visit the journal online (http://dx.doi. org/10.1136/bmjopen-2020042965).

Received 23 July 2020 Revised 23 December 2020 Accepted 30 December 2020

Check for updates

(C) Author(s) (or their employer(s)) 2021. Re-use permitted under CC BY-NC. No commercial re-use. See rights and permissions. Published by BMJ.

For numbered affiliations see end of article.

Correspondence to Dr Joseph Conigliaro; jconigliaro@northwell.edu

\section{ABSTRACT}

Objective To describe the pattern of hydroxychloroquine use and examine the association between

hydroxychloroquine use and clinical outcomes arising from changes in the US Food and Drug Administration (FDA)'s recommendation during the coronavirus disease 2019 (COVID-19) pandemic.

Design A retrospective cross-sectional analysis.

Setting and participants We included hospitalised adult patients at Northwell Health hospitals with confirmed COVID-19 infections between 1 March 2020 and 11 May 2020. We categorised changes in the FDA's recommendation as pre-FDA approval (1 March 2020-27 March 2020), FDA approval (28 March 2020-23 April 2020), and FDA warning (24 April 2020-11 May 2020). The hydroxychloroquine-treated group received at least one dose within 48 hours of hospital admission.

Primary outcome A composite of intubation and inpatient death.

Results The percentages of patients who were treated with hydroxychloroquine were 192/2202 (8.7\%) pre-FDA approval, 2902/6741 (43.0\%) FDA approval, and 176/1066 $(16.5 \%)$ FDA warning period $(p<0.001)$. Using propensity score matching, there was a higher rate of the composite outcome among patients treated with hydroxychloroquine (49/192, 25.5\%) compared with no hydroxychloroquine $(66 / 384,17.2 \%)$ in the pre-FDA approval period $(p=0.03)$ but not in the FDA approval period ( $25.5 \%$ vs $22.6 \%$, $\mathrm{p}=0.08)$ or the FDA warning $(21.0 \%$ vs $15.1 \%, p=0.11)$ periods. Coincidently, there was an increase in number of patients with COVID-19 and disease severity during the FDA approval period (24.1\% during FDA approval vs $21.4 \%$ during pre-FDA approval period had the composite outcome). Hydroxychloroquine use was associated with increased odds of the composite outcome during the preFDA approval period ( $\mathrm{OR}=1.65(95 \% \mathrm{Cl} 1.09$ to 2.51)) but not during the FDA approval ( $0 \mathrm{R}=1.17(95 \% \mathrm{Cl} 0.99$ to 1.39)) and FDA warning ( $\mathrm{OR}=1.50(95 \% \mathrm{Cl} 0.94$ to 2.39)) periods.

Conclusions Hydroxychloroquine use was associated with adverse clinical outcomes only during the pre-FDA approval period but not during the FDA approval and

\section{Strengths and limitations of this study}

- This study examines hydroxychloroquine use with changes in the US Food and Drug Administration (FDA)'s recommendations during a coronavirus disease 2019 (COVID-19) pandemic.

- The study uses data from a large integrated health system, which include a diverse population throughout New York City, Long Island, and Westchester County.

- This study uses propensity score matching within each FDA recommendation to ensure that patients admitted in the FDA approval period are not matched to patients in the pre-FDA approval or FDA warning period.

- Due to the observational study design, this study does not establish causal relationship between hydroxychloroquine treatment and COVID-19 clinical outcomes.

warning periods, even after adjusting for concurrent changes in the percentage of patients with COVID-19 treated with hydroxychloroquine and the number (and disease severity) of hospitalised patients with COVID-19 infections.

\section{INTRODUCTION}

Coronavirus disease 2019 (COVID-19), which causes severe acute respiratory syndrome, has spread globally. One consequence has been the unprecedented number of intensive care unit (ICU) admissions requiring mechanical ventilation in many countries. The mortality of patients on mechanical ventilation has been reported to be $60 \%-80 \%$ with an overall hospital mortality of $20 \%-25 \%$ during the beginning of the pandemic. ${ }^{2}$ More recent studies have shown lower inpatient mortality, but COVID-19 still causes significant 


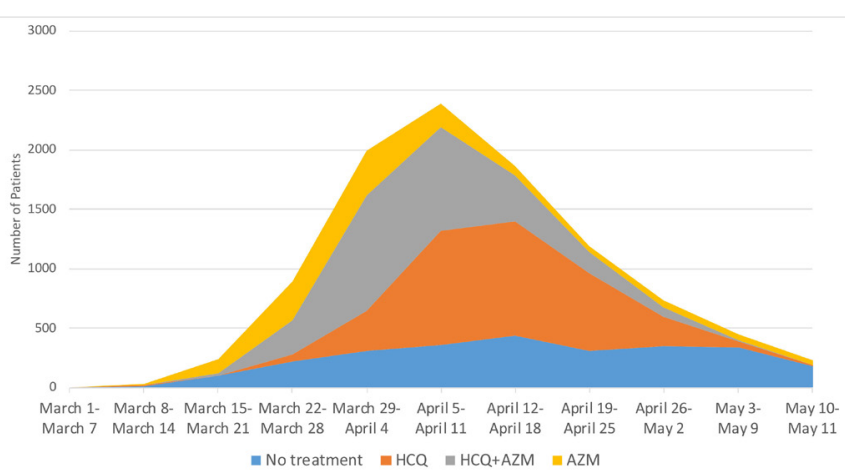

Figure 1 Number of patients with COVID-19 treated with different medications. AZM, azithromycin; $\mathrm{HCQ}$, hydroxychloroquine.

morbidity and mortality. ${ }^{34}$ As of 11 November 2020, over 53 million people have been infected with COVID-19 and 1.3 million deaths have been reported globally. ${ }^{5}$ Although multiple vaccines are emergently approved, they are limited in supply and it may take several months to immunise the general public. Therefore, the need to identify medications that are associated with slowed COVID-19 progression or decreased mortality remains urgent.

During the early months of the COVID-19 pandemic, hydroxychloroquine, a medication commonly used to prevent malaria infection and treat autoimmune diseases, gained global attention for its effectiveness in treating COVID-19 in vitro. ${ }^{6-11}$ Hydroxychloroquine is found to reduce the entry of coronavirus into a cell through interference with the terminal glycosylation of the angiotensin-converting enzyme 2 (ACE2) receptor, which inhibits viral replication. ${ }^{68}$ Additionally, hydroxychloroquine has immunomodulatory activity, and may inhibit cytokine production and prevent the occurrence of cytokine storm. ${ }^{12}$ Early studies examining the treatment of COVID-19 with hydroxychloroquine showed mixed results with some studies showing no average benefit in outcomes, including intubation or inpatient mortality, but other studies showing worse outcomes. ${ }^{13-22}$ A recent randomised clinical trial study examining the effects of hydroxychloroquine found no difference in clinical outcomes between patients treated with and without hydroxychloroquine. ${ }^{23}$

However, no study has accounted for how changes in recommendations for hydroxychloroquine by the US Food and Drug Administration (FDA) affected outcomes of patients treated for COVID-19. On 28 March 2020, the FDA issued an Emergency Use Authorization for hydroxychloroquine in the treatment of COVID-19 infection. During this time, there was also an increased number of hospitalised patients with COVID-19, which may have resulted in changes in hospital capacity and disease severity. ${ }^{5}$ Subsequently, on 24 April 2020, the FDA cautioned against using hydroxychloroquine for COVID-19 infection. ${ }^{24}$ These changes in the recommendation of hydroxychloroquine as a treatment for COVID-19 infection may have impacted whether patients were treated with hydroxychloroquine for COVID-19. These two events occurring concurrently could affect the association between hydroxychloroquine and COVID-19 outcomes. Therefore, using data from one of the largest healthcare systems in the US, we described the pattern of hydroxychloroquine use over time according to the FDA's position and examined the association between hydroxychloroquine use and patients' clinical outcomes based on changes in FDA's recommendation.

\section{METHODS}

\section{Setting}

This is a cross-sectional analysis of data from Northwell Health, the largest academic healthcare system in New York. Northwell Health serves approximately 11 million patients throughout Long Island, New York City, and Westchester County and has 23 affiliated healthcare facilities, including 12 acute care hospitals.

\section{Data source}

Data for this study were obtained from the enterprise's inpatient electronic health record (Sunrise Clinical Manager, Allscripts, Chicago, Illinois, USA), which covers 12 of Northwell Health's hospitals.

\section{Study population}

The study population included all adult patients $(n=13258)$ aged 18 years and older and hospitalised at one of Northwell Health's 12 acute care hospitals between 1 March 2020 and 11 May 2020 with a diagnosis of COVID-19 confirmed by a positive result on PCR testing of a nasopharyngeal sample. Patients with multiple COVID-19 tests were considered to have a confirmed COVID-19 infection if any of the repeated tests within the same hospitalisation returned positive. We excluded patients who died or were intubated within 1 day of hospitalisation because their clinical outcomes were likely predetermined by prehospitalisation factors. We also excluded patients who were discharged within 1 day of admission. Patients who were admitted to the obstetrics service were excluded as all obstetrics patients were screened for COVID-19 on their admission. For patients with multiple hospitalisations for COVID-19, we used their first hospitalisation with a confirmed diagnosis of COVID-19. We excluded 3249 patients who did not meet the inclusion and exclusion criteria.

\section{Exposure}

Patients were identified as treated with hydroxychloroquine if they received at least one dose within 48 hours of admission. The control group for this analysis consisted of patients who were not treated with hydroxychloroquine within 48 hours of admission. Patients who did not initially receive hydroxychloroquine within 48 hours but received the medication later in their hospitalisation were kept in the control group. We excluded patients with COVID-19 who were treated with azithromycin or a 
Table 1 Patient characteristics before propensity score matching, number (percentage) for categorical variable and mean (SD) for continuous variable

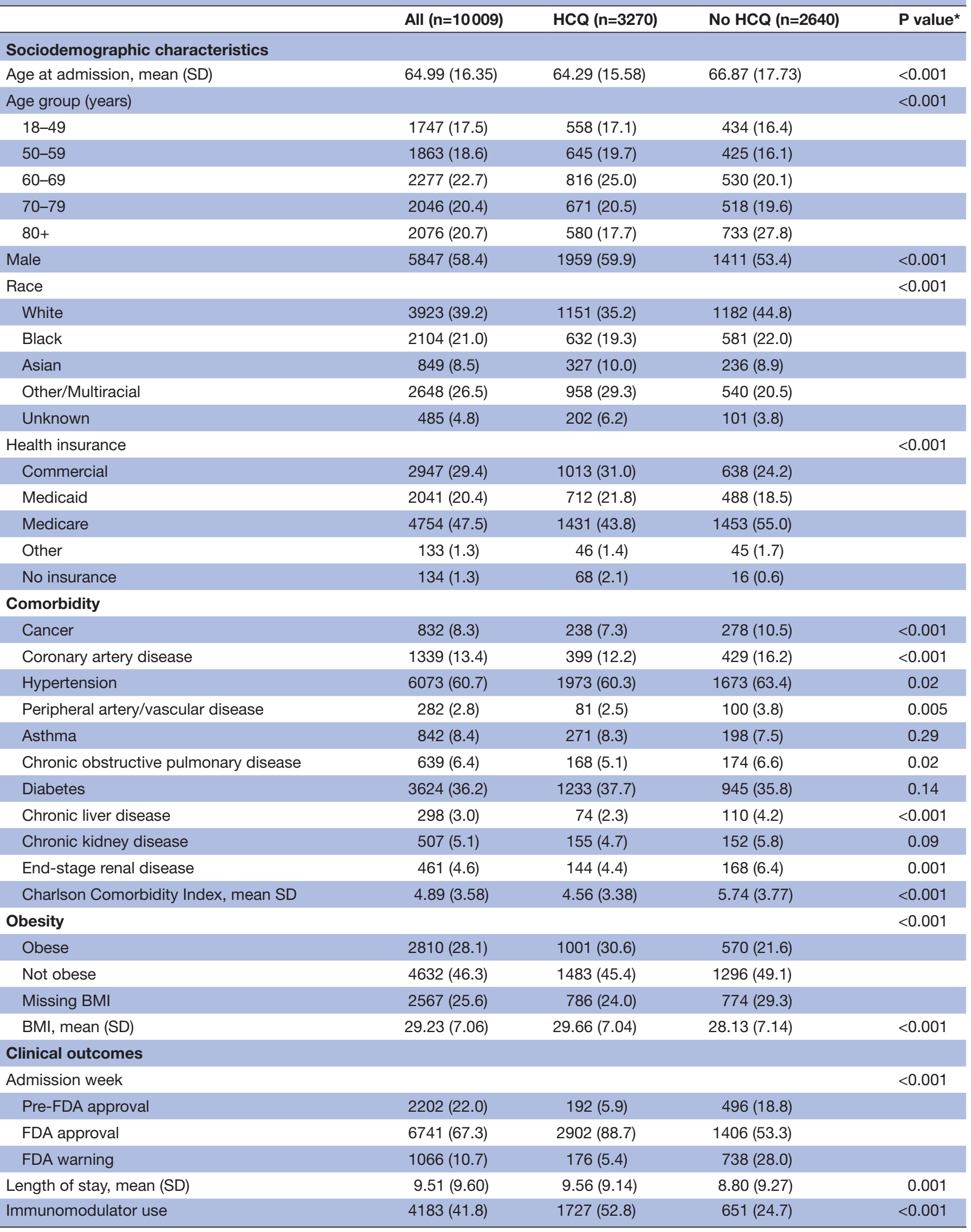


Table 1 Continued

\begin{tabular}{|c|c|c|c|c|}
\hline & All $(n=10009)$ & HCQ $(n=3270)$ & No HCQ $(n=2640)$ & P value* \\
\hline ICU stay & 1985 (19.8) & $583(17.8)$ & $426(16.1)$ & 0.09 \\
\hline Mechanical ventilation & $1314(13.1)$ & $437(13.4)$ & $186(7.0)$ & $<0.001$ \\
\hline Composite outcome & $2413(24.1)$ & $764(23.4)$ & $538(20.4)$ & 0.007 \\
\hline
\end{tabular}

${ }^{*}$ Comparing hydroxychloroquine group with no treatment group.

BMI, body mass index; FDA, Food and Drug Administration; HCQ, hydroxychloroquine; ICU, intensive care unit.

combination of hydroxychloroquine and azithromycin. We also excluded patients who were intubated prior to getting their first dose of hydroxychloroquine within 48 hours of admission.

\section{Outcomes}

The primary outcome of interest was a composite outcome of time to intubation or time to inpatient death. Time until composite event was censored at time of discharge for patients who were discharged alive with no intubation during their hospitalisation. The rationale for the combined primary outcome was twofold: (1) many patients who deteriorated clinically died without being intubated, often due to transition to palliative care and (2) hospitalisation stays for intubated patients with COVID-19 have been very long, and many intubated patients with COVID-19 at the time of the analyses may not ultimately survive. For a sensitivity analysis, we used death as the outcome. We tracked all patients who died or were not discharged until 1 June 2020.

\section{Covariates}

We collected data on patients' demographic characteristics and comorbidities. Demographic characteristics included age, sex, race/ethnicity, and health insurance (commercial, Medicaid, Medicare, other, and no insurance). We used patient-reported race and ethnicity information and categorised patients into one of five racial/ethnic groups: white, black, Asian, other/multiracial, and unknown/ declined. We also identified a subgroup of patients who received immunomodulatory medications, including steroids (prednisone or methylprednisolone), sarilumab, tocilizumab, anakinra, or colchicine, and included this information as a covariate. We identified the presence of the following comorbidities by International Statistical Classification of Disease and Related Health Problems, Tenth Revision coding: cancer, coronary artery disease, hypertension, asthma, chronic obstructive pulmonary disease, diabetes, chronic liver disease, chronic kidney disease, and end-stage renal disease. We calculated the Charlson Comorbidity Index, which predicts the 10-year survival of patients with multiple comorbidities as a measure of total comorbidity burden. ${ }^{25}$ The only covariate with missing data was body mass index (BMI), and we categorised the BMI group as not obese (BMI $<30 \mathrm{~kg} / \mathrm{m}^{2}$ ), obese (BMI $\geq 30 \mathrm{~kg} / \mathrm{m}^{2}$ ), and missing BMI.
We categorised changes in FDA's recommendation for hydroxychloroquine into three time periods: (1) preFDA approval (1 March 2020-27 March 2020), (2) FDA approval (28 March 2020-23 April 2020), and (3) FDA warning (24 April 2020-11 May 2020).

\section{Statistical analysis}

All analyses were performed using V.3.5.2 of the $\mathrm{R}$ Programming Language ( $\mathrm{R}$ Project for Statistical Computing, R Foundation, Vienna, Austria). We first performed $\chi^{2}$ and two-sample t-tests to compare patient characteristics treated with hydroxychloroquine with no hydroxychloroquine (control).

We used propensity score matching methods, 1:2 for the pre-FDA approval and the FDA warning periods and 1:1 for the FDA approval period, using the smaller group as a reference, within each period and applied the nearest-neighbour method to create a matched control sample. The propensity score matching was performed within each period so that patients admitted within the FDA approval period were not matched to patients in the pre-FDA approval or FDA warning periods, so as not to confound the effect of different FDA recommendations.

We then took the following approach to conduct the analysis. We first performed logistic regressions to compare the propensity score-matched hydroxychloroquine group with the control group. For a time-to-event analysis, we used the Kaplan-Meier survival estimate and log-rank test. We examined the Kaplan-Meier survival curves for the treatment group compared with the control group, separated by the different FDA recommendation periods. If a patient was discharged alive without intubation, data were censored at the time of hospital discharge. Then, we used Cox proportional-hazard regression models to estimate the association between the propensity-matched treatment group to the control group with respect to end point free survival time. We used the Schoenfeld residuals to test the proportional hazard assumption in the Cox model.

\section{RESULTS}

\section{Characteristics of the cohort}

From a cohort of 10009 patients, 3270 (32.7\%) were treated with hydroxychloroquine, 2640 (26.4\%) with neither hydroxychloroquine nor azithromycin, 1289 
Table 2 Patient characteristics after propensity score matching, number (percentage) for categorical variable and mean (SD) for continuous variable

\begin{tabular}{|c|c|c|c|c|c|c|c|c|c|}
\hline & \multicolumn{3}{|c|}{ Pre-FDA approval } & \multicolumn{3}{|c|}{ FDA approval } & \multicolumn{3}{|c|}{ FDA warning } \\
\hline & HCQ $(n=192)$ & $\begin{array}{l}\text { No HCQ } \\
(n=384)\end{array}$ & SMD & $\begin{array}{l}\text { HCQ } \\
(n=1406)\end{array}$ & $\begin{array}{l}\text { No HCQ } \\
(n=1406)\end{array}$ & SMD & $\begin{array}{l}\mathrm{HCQ} \\
(n=176)\end{array}$ & $\begin{array}{l}\text { No HCQ } \\
(n=352)\end{array}$ & SMD \\
\hline $\begin{array}{l}\text { Age at admission, } \\
\text { mean (SD) }\end{array}$ & $61.1(15.8)$ & $62.8(17.2)$ & 0.101 & $\begin{array}{l}67.8 \\
(15.8)\end{array}$ & $67.3(17.6)$ & 0.03 & $\begin{array}{l}66.2 \\
(16.2)\end{array}$ & $66.3(17.6)$ & 0.007 \\
\hline Male & $109(56.8)$ & $218(56.8)$ & $<0.001$ & $740(52.6)$ & $765(54.4)$ & 0.036 & $\begin{array}{l}92 \\
(52.3)\end{array}$ & $194(55.1)$ & 0.057 \\
\hline Race & & & 0.134 & & & 0.013 & & & 0.05 \\
\hline White & $91(47.4)$ & $180(46.9)$ & & $610(43.4)$ & $612(43.5)$ & & $\begin{array}{l}65 \\
(36.9)\end{array}$ & $136(38.6)$ & \\
\hline Black & 35 (18.2) & $86(22.4)$ & & $306(21.8)$ & $302(21.5)$ & & $\begin{array}{l}37 \\
(21.0)\end{array}$ & $69(19.6)$ & \\
\hline Unknown & $5(2.6)$ & $9(2.3)$ & & $50(3.6)$ & $53(3.8)$ & & $9(5.1)$ & $16(4.5)$ & \\
\hline Health insurance & & & 0.257 & & & 0.039 & & & 0.036 \\
\hline Commercial & $91(47.4)$ & $134(34.9)$ & & $306(21.8)$ & $321(22.8)$ & & $\begin{array}{l}44 \\
(25.0)\end{array}$ & $92(26.1)$ & \\
\hline Medicaid & 30 (15.6) & $72(18.8)$ & & $246(17.5)$ & $249(17.7)$ & & 31 17.6) & $62(17.6)$ & \\
\hline Medicare & $71(37.0)$ & $178(46.4)$ & & 819 (58.3) & 805 (57.3) & & $\begin{array}{l}92 \\
(52.3)\end{array}$ & $182(51.7)$ & \\
\hline Other & $0(0.0)$ & $0(0.0)$ & & $27(1.9)$ & $22(1.6)$ & & $6(3.4)$ & $11(3.1)$ & \\
\hline No insurance & $0(0.0)$ & $0(0.0)$ & & $8(0.6)$ & $9(0.6)$ & & $3(1.7)$ & $5(1.4)$ & \\
\hline \multicolumn{10}{|l|}{ Comorbidity } \\
\hline Asthma & $24(12.5)$ & $35(9.1)$ & 0.109 & $88(6.3)$ & $100(7.1)$ & 0.034 & $17(9.7)$ & $32(9.1)$ & 0.019 \\
\hline $\begin{array}{l}\text { Chronic obstructive } \\
\text { pulmonary disease }\end{array}$ & $9(4.7)$ & $23(6.0)$ & 0.058 & $83(5.9)$ & $87(6.2)$ & 0.012 & $14(8.0)$ & $29(8.2)$ & 0.01 \\
\hline Diabetes & $70(36.5)$ & $138(35.9)$ & 0.011 & $515(36.6)$ & $508(36.1)$ & 0.01 & $\begin{array}{l}68 \\
(38.6)\end{array}$ & $131(37.2)$ & 0.029 \\
\hline Chronic liver disease & $7(3.6)$ & $15(3.9)$ & 0.014 & $47(3.3)$ & $56(4.0)$ & 0.034 & $7(4.0)$ & $19(5.4)$ & 0.067 \\
\hline $\begin{array}{l}\text { Chronic kidney } \\
\text { disease }\end{array}$ & $11(5.7)$ & $25(6.5)$ & 0.033 & $84(6.0)$ & $80(5.7)$ & 0.012 & $8(4.5)$ & $17(4.8)$ & 0.013 \\
\hline $\begin{array}{l}\text { End-stage renal } \\
\text { disease }\end{array}$ & $12(6.2)$ & $27(7.0)$ & 0.031 & $99(7.0)$ & $101(7.2)$ & 0.006 & $4(2.3)$ & $8(2.3)$ & $<0.001$ \\
\hline $\begin{array}{l}\text { Charlson } \\
\text { Comorbidity Index, } \\
\text { mean SD }\end{array}$ & $4.23(3.19)$ & $4.73(3.32)$ & 0.152 & $\begin{array}{l}5.72 \\
(3.75)\end{array}$ & $\begin{array}{l}5.69 \\
(3.73)\end{array}$ & 0.008 & $\begin{array}{l}5.03 \\
(3.23)\end{array}$ & $\begin{array}{l}5.01 \\
(3.42)\end{array}$ & 0.005 \\
\hline Obesity & & & 0.198 & & & 0.022 & & & 0.027 \\
\hline Obese & $76(39.6)$ & $116(30.2)$ & & $289(20.6)$ & $292(20.8)$ & & $\begin{array}{l}50 \\
(28.4)\end{array}$ & $98(27.8)$ & \\
\hline Not obese & 69 (35.9) & $160(41.7)$ & & $678(48.2)$ & $663(47.2)$ & & $\begin{array}{l}84 \\
(47.7)\end{array}$ & $166(47.2)$ & \\
\hline
\end{tabular}

Continued 


\begin{tabular}{|c|c|c|c|c|c|c|c|c|c|}
\hline \multirow[b]{2}{*}{ Missing BMI } & \multicolumn{3}{|c|}{ Pre-FDA approval } & \multicolumn{3}{|c|}{ FDA approval } & \multicolumn{3}{|c|}{ FDA warning } \\
\hline & $47(24.5)$ & $108(28.1)$ & & $439(31.2)$ & $451(32.1)$ & & $\begin{array}{l}42 \\
(23.9)\end{array}$ & $88(25.0)$ & \\
\hline \multicolumn{10}{|l|}{ Clinical outcomes } \\
\hline $\begin{array}{l}\text { Length of stay, mean } \\
\text { (SD) }\end{array}$ & $10.88(11.20)$ & $10.48(11.79)$ & 0.035 & $\begin{array}{l}9.29 \\
(8.66)\end{array}$ & $\begin{array}{l}7.75 \\
(7.82)\end{array}$ & 0.187 & $\begin{array}{l}8.67 \\
(7.55)\end{array}$ & $\begin{array}{l}8.28 \\
(7.40)\end{array}$ & 0.053 \\
\hline Inpatient mortality & $31(16.1)$ & $55(14.3)$ & 0.272 & $318(22.6)$ & 294 (20.9) & 0.086 & $\begin{array}{l}32 \\
(18.2)\end{array}$ & $46(13.1)$ & 0.079 \\
\hline Composite outcome & $49(25.5)$ & $66(17.2)$ & 0.204 & $359(25.5)$ & $318(22.6)$ & 0.068 & $\begin{array}{l}37 \\
(21.0)\end{array}$ & $53(15.1)$ & 0.156 \\
\hline
\end{tabular}

BMI, body mass index; FDA, Food and Drug Administration; HCQ, hydroxychloroquine; SD, Standard deviation; SMD, Standardized mean difference.

(12.9\%) with azithromycin only, and 2810 (28.1\%) with the combination hydroxychloroquine and azithromycin. There were differences in the number of patients treated with or without hydroxychloroquine and/or azithromycin by admission period (figure 1).

We found significant differences in the use of hydroxychloroquine and patient characteristics based on changes to FDA's recommendation. Number and percentages of patients treated with hydroxychloroquine were 192/2202 $(8.7 \%)$ pre-FDA approval, 2902/6741 $(43.0 \%)$ during FDA approval, and 176/1066 (16.5\%) during the FDA warning period $(p<0.001)$. There was a significant increase in number of patients during the FDA approval period (28 March-23 April). During the pre-FDA approval period, there were 2202 patients admitted with COVID-19 infection, but in the following periods, the number of patients admitted with COVID-19 infections was 6741 (FDA approval period) and 1066 (FDA warning period). Throughout the study, and independent of FDA periods, there were differences in sociodemographic and clinical characteristics between the treatment group compared with the control group (table 1). Higher percentage of patients who were younger $(36.8 \%$ vs $32.5 \%$ were $<60$ years of age), male $(59.9 \%$ vs $53.4 \%)$, and had commercial insurance $(31.0 \%$ vs $24.2 \%)$ were treated with hydroxychloroquine $(\mathrm{p}<0.001)$. Presence of comorbidity, except for asthma, diabetes, and chronic kidney disease, was associated with hydroxychloroquine use (all $\mathrm{p}<0.05)$.

Hydroxychloroquine groups $(13.4 \%)$ had higher rates of intubation compared with the control group (7.0\%) $(\mathrm{p}<0.001)$. Inpatient mortality was $20.2 \%$ for hydroxychloroquine vs $18.3 \%$ for no hydroxychloroquine treatment $(p=0.01)$. A significantly higher percentage of patients treated with hydroxychloroquine $(23.4 \%)$ reached the composite outcome compared with the control group $(20.4 \%) \quad(p=0.007)$. A higher percentage of patients on hydroxychloroquine $(52.8 \%)$ were treated concurrently with immunomodulatory medications compared with the control group $(24.7 \%) \quad(\mathrm{p}<0.001)$.
After propensity score matching within each time period, sociodemographic characteristics and comorbidity were similar between hydroxychloroquine and no hydroxychloroquine group (table 2). There were 576 patients in the preFDA approval period, 2812 patients in the FDA approval period, and 528 in the FDA warning period. There was a higher composite outcome among patients treated with hydroxychloroquine $(25.5 \%)$ compared with no hydroxychloroquine $(17.2 \%)$ during the pre-FDA approval period $(\mathrm{p}=0.03)$ but no difference in the number of composite outcomes between hydroxychloroquine and no hydroxychloroquine groups in the FDA approval period $(25.5 \%$ vs $22.6 \%$, $\mathrm{p}=0.08)$ or the FDA warning period $(21.0 \%$ vs $15.1 \%, \mathrm{p}=0.11)$ (table 3). In the univariate analysis, hydroxychloroquine use was associated with increased odds of the composite outcome during the pre-FDA approval period (OR=1.65 (95\% CI 1.09 to 2.51)) but there was no association during the FDA approval (OR=1.17 (95\% CI 0.99 to 1.39)) as well as the FDA warning period ( $\mathrm{OR}=1.50$ [(95\% CI 0.94 to 2.39$)$ ).

\section{Time-to-event analysis}

Figure 2 shows the Kaplan-Meier curves of freedom from the composite end point of intubation and inpatient mortality during the pre-FDA approval period, the FDA approval period, or the FDA warning period. The Cox proportional hazard regression models showed hydroxychloroquine use was associated with the composite outcome of intubation and inpatient mortality during the pre-FDA approval ( $\mathrm{HR}=1.70$ (95\% CI 1.17 to 2.48)) and the FDA warning (HR=1.53 (95\% CI 1.00 to 2.34)) period but not during the FDA approval period ( $\mathrm{HR}=1.03(95 \%$ CI 0.88 to 1.20$]$ ) (table 3 ). The proportional hazards assumption was met in the Cox regression model.

\section{DISCUSSION}

In our study, while there were changes in percentage of patients with COVID-19 treated with hydroxychloroquine with FDA's recommendations, there was also a fluctuation 
Table 3 Association between hydroxychloroquine (HCQ) use and the composite end point in the crude analysis and propensity score matched analysis

\begin{tabular}{|c|c|c|}
\hline Analysis & Results & P value* \\
\hline \multicolumn{3}{|c|}{ Composite outcome among patients at risk, $\mathrm{n}(\%)$} \\
\hline \multicolumn{3}{|c|}{ Before propensity score matching } \\
\hline \multicolumn{3}{|l|}{ All periods } \\
\hline Overall & 2080/10009 (23.9) & - \\
\hline $\mathrm{HCQ}$ & $764 / 3270(23.4)$ & 0.007 \\
\hline No HCQ & $538 / 2640(20.4)$ & \\
\hline \multicolumn{3}{|c|}{ After propensity score matching } \\
\hline \multicolumn{3}{|l|}{ Pre-FDA approval } \\
\hline $\mathrm{HCQ}$ & 49/192 (25.5) & 0.03 \\
\hline No HCQ & 66/384 (17.2) & \\
\hline \multicolumn{3}{|l|}{ FDA approval } \\
\hline $\mathrm{HCQ}$ & $359 / 1406(25.5)$ & 0.08 \\
\hline No HCQ & $318 / 1406(22.6)$ & \\
\hline \multicolumn{3}{|l|}{ FDA warning } \\
\hline $\mathrm{HCQ}$ & $37 / 176(21.0)$ & 0.11 \\
\hline No HCQ & $53 / 352(15.1)$ & \\
\hline \multicolumn{3}{|c|}{ Univariate analysis-OR $(95 \% \mathrm{Cl})^{*}$} \\
\hline $\begin{array}{l}\text { Pre-FDA approval } \\
\text { (reference: no HCQ) }\end{array}$ & 1.65 (1.09 to 2.51$)$ & 0.02 \\
\hline $\begin{array}{l}\text { FDA approval (reference: } \\
\text { no HCQ) }\end{array}$ & 1.17 (0.99 to 1.39$)$ & 0.07 \\
\hline $\begin{array}{l}\text { FDA warning (reference: no } \\
\text { HCQ) }\end{array}$ & 1.50 (0.94 to 2.39$)$ & 0.09 \\
\hline \multicolumn{3}{|c|}{ Propensity score matched analyses - HR $(95 \% \mathrm{CI})^{*}$} \\
\hline $\begin{array}{l}\text { Pre-FDA approval } \\
\text { (reference: no HCQ) }\end{array}$ & 1.70 (1.17 to 2.48$)$ & 0.005 \\
\hline $\begin{array}{l}\text { FDA approval (reference: } \\
\text { no HCQ) }\end{array}$ & $1.03(0.88$ to 1.20$)$ & 0.72 \\
\hline $\begin{array}{l}\text { FDA warning (reference: no } \\
\mathrm{HCQ} \text { ) }\end{array}$ & $1.53(1.00$ t 2.34) & 0.05 \\
\hline
\end{tabular}

*Comparing HCQ group with no treatment group.

FDA, Food and Drug Administration; $\mathrm{HCQ}$, hydroxychloroquine; $\mathrm{HR}$, hazard ratio; OR, odds ratio.

of the number of hospitalised patients with COVID-19 infections during the FDA approval period. Hydroxychloroquine treatment was associated with increased composite outcome of intubation or death during preFDA approval period but not during FDA approval or FDA warning period. The overall association of hydroxychloroquine treatment among patients with COVID-19 in our cohort was similar to previous studies showing no association between the treatment and primary end point of intubation or death. ${ }^{1314}$

Although not captured in our study, during the FDA approval period, hospitals had to manage sudden increases in critically ill patients. As hospitals were reaching their maximum capacity, coordinated efforts were made to ensure that there were adequate ventilators

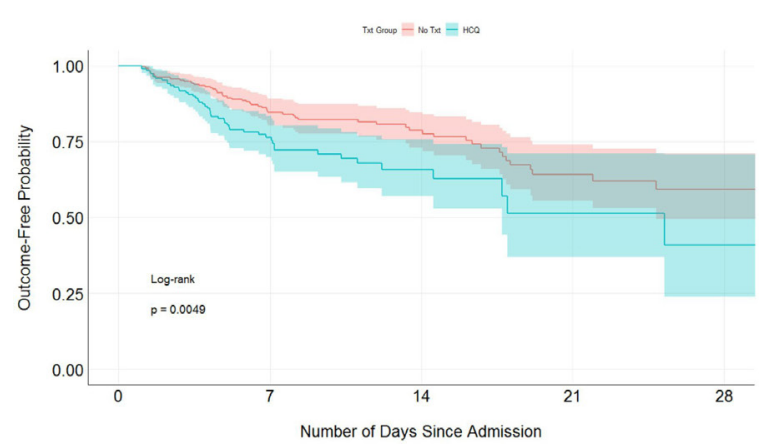

A Pre-FDA approval

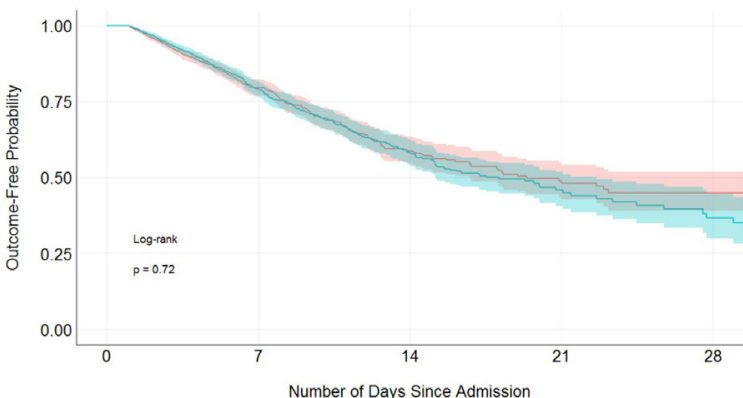

B FDA approval

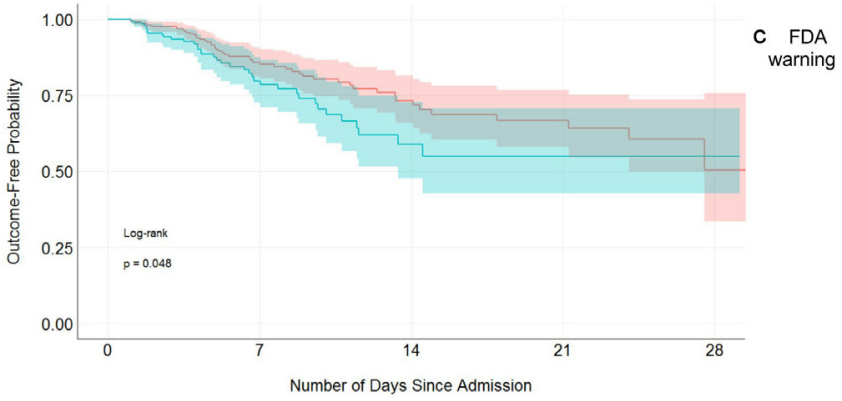

Figure 2 Kaplan-Meier curve showing freedom from composite end point of intubation or inpatient mortality by different time period. FDA, Food and Drug Administration; $\mathrm{HCQ}$, hydroxychloroquine.

for patients with pulmonary complications, goals of care discussions for patients with poor prognosis, and an increase in ambulatory management to ensure medical care for all patients. ${ }^{26-28}$ Therefore, patients who were admitted during this period may have had more severe disease, including hypoxia, requiring ventilators. This hypothesis is also consistent with the higher proportions of patients experiencing the composite outcome during this period. There was also an increased use of immunomodulators, which were more often used for patients with more complications, including acute respiratory distress syndrome, acute kidney injury, thrombosis, and so on. ${ }^{1290}$ Therefore, regardless of whether they were being treated with hydroxychloroquine or not, patients admitted during the FDA approval period had overall worse outcomes compared with patients admitted during other periods. Because of such differences in patient disease severity and hospital settings, we used propensity score matching of patients within each period so that the patients treated in the pre-FDA approval or FDA warning periods were not matched with patients treated in the FDA approval period. 
The lack of efficacy of hydroxychloroquine could be attributed to the severity of disease among patients receiving medication. The hypothesised mechanism of action of hydroxychloroquine is that it prevents the virus from entering cells and blocks viral replication. ${ }^{6-8}$ These patients were hospitalised because of a severe course of disease; therefore, it is likely that viral replication was already high when hydroxychloroquine was administered. This may be particularly true for patients who were hospitalised during the FDA approved period because hospitals had a high number of patients with COVID-19 requiring inpatient care. Also, hydroxychloroquine may have been administered to more severely ill patients and subsequently was associated with higher risk of intubation and/or inpatient mortality. We addressed this by comparing propensity score matching patients treated with hydroxychloroquine with no hydroxychloroquine. Of note, higher doses of hydroxychloroquine have been associated with adverse intermediate outcomes, including QTc prolongation, in another study. ${ }^{31}$

This study has several limitations. Due to the observational study design, this study does not establish causal relationships between medication treatment and outcomes. Also, this study is limited to the inpatient setting; therefore, the study findings are not generalisable to outpatient or community settings. Although we did attempt to adjust for covariates, it is possible that the severity of illness and precise timing of treatment also may have influenced the association of these medications with the outcome. There may be a subset of patients who were taking hydroxychloroquine prescribed by their ambulatory providers prior to their hospitalisation. It is possible that some patients in the no-hydroxychloroquine group were taking the medications or already had completed their 5-day course prior to hospitalisation. There was a subset of patients in the control group who were treated with hydroxychloroquine or azithromycin after 48 hours because of their disease progression. The changes in the FDA's recommendations probably also caused some patients admitted during the pre-FDA approval period to be treated with hydroxychloroquine during their prolonged hospitalisations. This could result in bias towards the null-that is, erroneously concluding no difference between hydroxychloroquine and control (type II error). The strength of this study, however, is the inclusion of a large, diverse populationincluding racial and ethnic minorities-extending the generalisability of our study.

Regardless of FDA's recommendation for the drug, we did not observe any beneficial association of hydroxychloroquine use throughout the study period. In addition to changes in the FDA's recommendation, this study addresses alterations in case mix due to changes in number of patients with COVID-19 being hospitalised. This study further confirms that hydroxychloroquine does not alter the clinical course among patients with COVID-19 infections in the inpatient setting where patients have more severe diseases. Additionally, recent evidence suggests that hydroxychloroquine treatment does not alter clinical outcomes among patients with milder symptoms and is not effective as pharmacological prophylaxis. ${ }^{32}$ On 15 June 2020, the FDA revoked the Emergency Use Authorization for hydroxychloroquine in the treatment of COVID-19 infection; this will further decrease the number of patients with COVID-19 being treated with hydroxychloroquine. ${ }^{34}$ These study results should not be used as guidance on whether or not to treat patients with COVID-19 with or without hydroxychloroquine due to its observational design.

\section{Author affiliations}

${ }^{1}$ Department of Medicine, Donald and Barbara Zucker School of Medicine at Hofstra/Northwell, Northwell Health, Hempstead, New York, USA

${ }^{2}$ Institute of Health Innovations and Outcomes Research, Feinstein Institutes for Medical Research, Northwell Health, Manhasset, New York, USA

${ }^{3}$ Department of Information Services, Northwell Health, New Hyde Park, New York, USA

${ }^{4}$ Biostatistics Unit, Feinstein Institutes for Medical Research, Northwell Health, Manhasset, New York, USA

Collaborators The Northwell Health COVID-19 Research Consortium: Stuart L. Cohen, MD (Institute of Health Innovations and Outcome Research, Feinstein Institutes for Medical Research, Northwell Health, Manhasset, New York; Donald and Barbara Zucker School of Medicine at Hofstra/Northwell, Northwell Health, Hempstead, New York); Charlotte Kvasnovsky, MD, PhD, MPH (Donald and Barbara Zucker School of Medicine at Hofstra/Northwell, Northwell Health, Hempstead, New York); Stephen C. Machnicki, MD, FCCP (Donald and Barbara Zucker School of Medicine at Hofstra/Northwell, Northwell Health, Hempstead, New York); Alex Makhnevich, MD (Institute of Health Innovations and Outcome Research, Feinstein Institutes for Medical Research, Northwell Health, Manhasset, New York; Donald and Barbara Zucker School of Medicine at Hofstra/Northwell, Northwell Health, Hempstead, New York); Prashant Malhotra, MD (Institute of Health Innovations and Outcome Research, Feinstein Institutes for Medical Research, Northwell Health, Manhasset, New York; Donald and Barbara Zucker School of Medicine at Hofstra/ Northwell, Northwell Health, Hempstead, New York); Lyndonna Marrast, MD, MPH (Institute of Health Innovations and Outcome Research, Feinstein Institutes for Medical Research, Northwell Health, Manhasset, New York; Donald and Barbara Zucker School of Medicine at Hofstra/Northwell, Northwell Health, Hempstead, New York); Ramanak Mitra, MD (Donald and Barbara Zucker School of Medicine at Hofstra/Northwell, Northwell Health, Hempstead, New York); Ernesto P. Molmenti, MD (Donald and Barbara Zucker School of Medicine at Hofstra/Northwell, Northwell Health, Hempstead, New York); Sonali Narain, MBBS, MPH (Institute of Health Innovations and Outcome Research, Feinstein Institutes for Medical Research, Northwell Health, Manhasset, New York; Donald and Barbara Zucker School of Medicine at Hofstra/Northwell, Northwell Health, Hempstead, New York); M. Wasif Saif, MD, MBBS (Institute of Health Innovations and Outcome Research, Feinstein Institutes for Medical Research, Northwell Health, Manhasset, New York; Donald and Barbara Zucker School of Medicine at Hofstra/Northwell, Northwell Health, Hempstead, New York); Sanjaya Satapathy, MD (Donald and Barbara Zucker School of Medicine at Hofstra/Northwell, Northwell Health, Hempstead, New York); Shalin Shah, MD (Donald and Barbara Zucker School of Medicine at Hofstra/Northwell, Northwell Health, Hempstead, New York).

Contributors Concept and design: EJK, KC, JSH, KWD, ML, JC. Acquisition: KC, JSH. Drafting of the manuscript: EJK, KC, SA, JJ. Critical revision of the manuscript for important intellectual content: all authors. Statistical analysis: KC, ML. Obtained funding: KWD. Administrative, technical or material support: KWD, JC. Supervision: ML, KWD, JC.

Funding This work was supported by grants R24AG064191 from the National Institute on Aging of the National Institutes of Health and R01LM012836 from the National Library of Medicine of the National Institutes of Health.

Competing interests None declared.

Patient and public involvement Patients and/or the public were not involved in the design, conduct, reporting, or dissemination plans of this research.

Patient consent for publication Not required. 
Ethics approval The Institutional Review Board for the Feinstein Institutes for Medical Research at Northwell Health approved this case series as minimalrisk research using data collected for routine clinical practice and waived the requirement for informed consent.

Provenance and peer review Not commissioned; externally peer reviewed.

Data availability statement Data are available on reasonable request. The data that support the findings of this study are available on request from COVID19@ northwell.edu. The data are not publicly available due to restrictions as they could compromise the privacy of research participants.

Open access This is an open access article distributed in accordance with the Creative Commons Attribution Non Commercial (CC BY-NC 4.0) license, which permits others to distribute, remix, adapt, build upon this work non-commercially, and license their derivative works on different terms, provided the original work is properly cited, appropriate credit is given, any changes made indicated, and the use is non-commercial. See: http://creativecommons.org/licenses/by-nc/4.0/.

\section{ORCID iD}

Eun Ji Kim http://orcid.org/0000-0002-4087-5261

\section{REFERENCES}

1 Wu C, Chen X, Cai Y, et al. Risk factors associated with acute respiratory distress syndrome and death in patients with coronavirus disease 2019 pneumonia in Wuhan, China. JAMA Intern Med 2020;180:934.

2 Richardson S, Hirsch JS, Narasimhan M, et al. Presenting characteristics, comorbidities, and outcomes among 5700 patients hospitalized with COVID-19 in the new York City area. JAMA 2020;323:2052.

3 Angeli F, Bachetti T, Maugeri Study G, Maugeri Study Group. Temporal changes in co-morbidities and mortality in patients hospitalized for COVID-19 in Italy. Eur J Intern Med 2020;82:123-5.

4 Horwitz LI, Jones SA, Cerfolio RJ, et al. Trends in COVID-19 riskadjusted mortality rates. J Hosp Med 2020 doi:10.12788/jhm.3552

5 The Center for Systems Science and Enginnering at Johns Hopkins University. COVID-19 dashboard. Available: https://www.arcgis. com/apps/opsdashboard/index.html\#/bda7594740fd40299423467b 48e9ecf6 [Accessed 10 Jun 2020].

6 Yao X, Ye F, Zhang M. In vitro antiviral activity and projection of optimized dosing design of hydroxychloroquine for the treatment of severe acute respiratory syndrome coronavirus 2 (SARS-CoV-2). Clin Infect Dis 2020.

7 Wang M, Cao R, Zhang L, et al. Remdesivir and chloroquine effectively inhibit the recently emerged novel coronavirus (2019nCoV) in vitro. Cell Res 2020;30:269-71.

8 Vincent MJ, Bergeron E, Benjannet S, et al. Chloroquine is a potent inhibitor of SARS coronavirus infection and spread. Virol J 2005;2:69.

9 Liu J, Cao R, Xu M, et al. Hydroxychloroquine, a less toxic derivative of chloroquine, is effective in inhibiting SARS-CoV-2 infection in vitro. Cell Discov 2020;6:16.

10 Andreani J, Le Bideau M, Duflot I, et al. In vitro testing of combined hydroxychloroquine and azithromycin on SARS-CoV-2 shows synergistic effect. Microb Pathog 2020;145:104228.

11 Grassin-Delyle S, Salvator $\mathrm{H}$, Brollo M, et al. Chloroquine inhibits the release of inflammatory cytokines by human lung explants. Clin Infect Dis 2020;71:2265-8.

12 Schrezenmeier E, Dörner T. Mechanisms of action of hydroxychloroquine and chloroquine: implications for rheumatology. Nat Rev Rheumatol 2020;16:155-66.

13 Geleris J, Sun Y, Platt J, et al. Observational study of hydroxychloroquine in hospitalized patients with Covid-19. N Engl J Med 2020;382:2411-8.

14 Rosenberg ES, Dufort EM, Udo T, et al. Association of treatment with hydroxychloroquine or azithromycin with in-hospital mortality in patients with COVID-19 in New York state. JAMA 2020;323:2493.
15 Tang W, Cao Z, Han M, et al. Hydroxychloroquine in patients with mainly mild to moderate coronavirus disease 2019: open label, randomised controlled trial. BMJ 2020;369:m1849.

16 Molina JM, Delaugerre C, Le Goff J, et al. No evidence of rapid antiviral clearance or clinical benefit with the combination of hydroxychloroquine and azithromycin in patients with severe COVID-19 infection. Med Mal Infect 2020;50:384.

17 Magagnoli J, Narendran S, Pereira F. Outcomes of hydroxychloroquine usage in United States veterans hospitalized with Covid-19. medRxiv 2020:127. doi:10.1016/j.medj.2020.06.001

18 Fiolet T, Guihur A, Rebeaud ME. Effect of hydroxychloroquine with or without azithromycin on the mortality of coronavirus disease 2019 (COVID-19) patients: a systematic review and meta-analysis. Clin Microbiol Infect 2020.

19 Gautret P, Lagier JC, Parola P. Hydroxychloroquine and azithromycin as a treatment of COVID-19: results of an open-label nonrandomized clinical trial. Int J Antimicrob Agents 2020;105949.

20 Gao J, Tian Z, Yang X. Breakthrough: chloroquine phosphate has shown apparent efficacy in treatment of COVID-19 associated pneumonia in clinical studies. Biosci Trends 2020;14:72-3.

21 Chen Z, Hu J, Zhang Z. Efficacy of hydroxychloroquine in patients with COVID-19: results of a randomized clinical trial. medRxiv 2020.

22 Arshad S, Kilgore P, Chaudhry ZS, et al. Treatment with hydroxychloroquine, azithromycin, and combination in patients hospitalized with COVID-19. Int J Infect Dis 2020;97:396-403.

23 Self WH, Semler MW, Leither LM, et al. Effect of hydroxychloroquine on clinical status at 14 days in hospitalized patients with COVID-19. JAMA 2020;324:2165.

24 Hydroxychloroquine or Chloroquine for COVID-19. Drug safety communication - FDA cautions against use outside of the hospital setting or a clinical trial due to risk of heart rhythm problems. U.S. food \& drug administration. Available: https://www.fda.gov/ safety/medical-product-safety-information/hydroxychloroquine-orchloroquine-covid-19-drug-safety-communication-fda-cautionsagainst-use [Accessed 15 May 2020].

25 Charlson ME, Pompei P, Ales KL, et al. A new method of classifying prognostic comorbidity in longitudinal studies: development and validation. J Chronic Dis 1987;40:373-83.

26 Curtis JR, Kross EK, Stapleton RD. The importance of addressing advance care planning and decisions about do-not-resuscitate orders during novel coronavirus 2019 (COVID-19). JAMA 2020.

27 Greenhalgh T, Koh GCH, Car J. Covid-19: a remote assessment in primary care. BMJ 2020;368:m1182.

28 White DB, Lo B. A framework for rationing ventilators and critical care beds during the COVID-19 pandemic. JAMA 2020;323:1773.

29 Hirsch JS, JH N, Ross DW. Acute kidney injury in patients hospitalized with Covid-19. Kidney Int 2020.

30 Connors JM, Levy JH. COVID-19 and its implications for thrombosis and anticoagulation. Blood 2020;135:2033-40.

31 Borba MGS, Val FFA, Sampaio VS, et al. Effect of high vs low doses of chloroquine diphosphate as adjunctive therapy for patients hospitalized with severe acute respiratory syndrome coronavirus 2 (SARS-CoV-2) infection: a randomized clinical trial. JAMA Netw Open 2020;3:e208857.

32 Abella BS, Jolkovsky EL, Biney BT, et al. Efficacy and safety of hydroxychloroquine vs placebo for pre-exposure SARS-CoV-2 prophylaxis among health care workers: a randomized clinical trial. JAMA Intern Med 2020 doi:10.1001/jamainternmed.2020.6319

33 Boulware DR, Pullen MF, Bangdiwala AS, et al. A randomized trial of hydroxychloroquine as postexposure prophylaxis for Covid-19. N Engl J Med 2020;383:517-25.

34 Coronavirus (COVID-19) update: FDA Revokes emergency use authorization for chloroquine and hydroxychloroquine. U.S. foods and drug administration. Available: https://www.fda.gov/newsevents/press-announcements/coronavirus-covid-19-update-fdarevokes-emergency-use-authorization-chloroquine-and [Accessed 20 Jun 2020]. 